\title{
Principles for public space design, planning to do better
}

\author{
Matthew Carmona ${ }^{1}$
}

Published online: 21 August 2018

(C) The Author(s) 2018

\begin{abstract}
This paper sets out a series of normative principles for planners and others to use when planning for and regulating public space design and management. Based on an exhaustive examination of public space in London, the substance of which is reported elsewhere, a first section sets out three overarching principles relating to the critical but often missing strategic planning framework for the development and regeneration of public spaces. A second and final section sets out seven more detailed considerations for evaluating the quality of public space design. This is an unashamedly positive framework for shaping public space, based on the notion that public spaces in our cities come in many different forms and guises, but collectively add huge value to the experience and potential of urban areas. Consequently, they deserve serious consideration by those with regulatory and other responsibilities for their delivery.
\end{abstract}

Keywords Public space · Design principles · Planning

\section{Introduction}

Public spaces range in form from informal street corners to grand civic set pieces. At a larger scale, formal public spaces have long had an important role as the perceived centres of settlements of all types and as the focus for public life, activities and events. At a smaller scale, they might simply be somewhere to rest, hang out, or play whilst providing a visual pause in the flow of streets

\footnotetext{
Matthew Carmona

m.carmona@ucl.ac.uk

1 The Bartlett School of Planning, UCL, London, UK
}

through urban areas. They encompass everything from traditional squares, to incidental urban spaces, to a range of new sorts of spaces (e.g. Cho et al. 2016) that challenge our perceptions-physically, socially and in terms of their management—about what public spaces should be (Fig. 1).

What is clear is that since the 1980s, public spaces of all forms have witnessed a renaissance in that they have increasingly become a key component of many regeneration and development schemes (both residential and commercial), worldwide, with far-reaching impacts on how the resulting places are perceived and used (Crowhurst Lennard and Lennard 1995; Corbett 2004). In such a context, it is vitally important to design public spaces well, although experience suggests that often our ambition is not met by the reality. When we do get them right, however, highquality public spaces offer huge economic, social and environmental benefits to their localities and communities (CABE 2004a).

This paper draws on research conducted in London (Carmona and Wunderlich 2012) to propose a set of rules, first, relating to the critical planning considerations for the development and regeneration of public spaces, and second, concerning the more detailed considerations for evaluating the quality of public space design. In doing so, it builds on, organises and better articulates a set of new normative principles for public space that stemmed from the research underpinning this paper and that were originally offered as a provisional attempt to re-theorise public space discourse on the basis of the actual experiences of public space creation, use and management, rather than simply on the basis of its critique (Carmona 2015). The original research involved a London-wide mapping of new and regenerated public spaces constructed between 1980 and 2012 across the city; a 'quick and dirty' impressionistic survey of 130 of these; and the more detailed analysis of 14 
Fig. 1 Sky Garden, London-a new private 'public space' on top of the Walkie Talkie tower negotiated as part of the planning permission. Free to enter, but you need to book in advance, obtain a ticket and pass through security

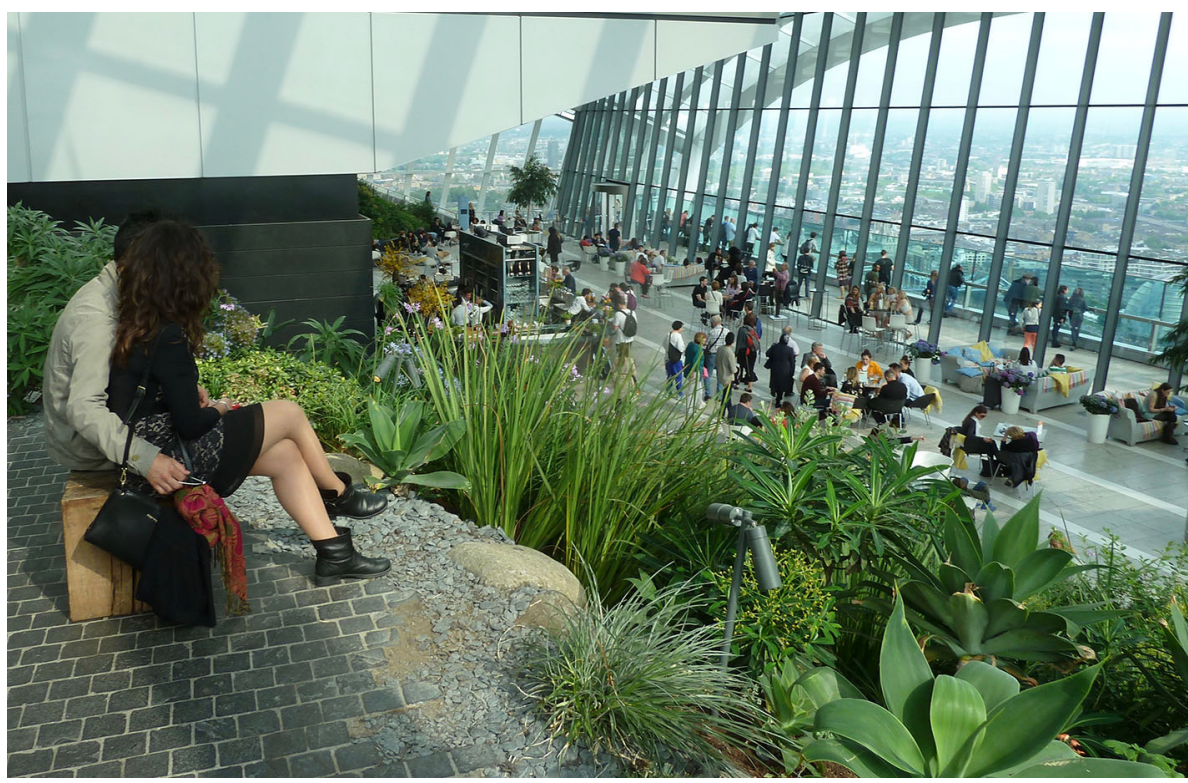

case studies reflecting the diversity of space types encountered. The case studies involved the gathering of 70 stakeholder narratives (with those who had been involved in their creation and or on-going management), 650 interviews with public space users across the spaces, time-lapse observations to record how each space was used, morphological analysis and the collection of secondary data from the local press and from relevant policy documents.

\section{Planning for public spaces}

The issue of delivering better public spaces is seen here first through the prism of planning because planners have a critical role to play in the creation and shaping of public spaces; a role that manifests itself in two distinct ways. First, planners are often the initiators of public space projects, for example, recognising the need and potential for new or regenerated public spaces in particular locations through the auspices of proactive site or area-based plans, frameworks and briefs, or otherwise encouraging them in policy. Second, planners are the guardians of how public spaces come into being through the regulatory processes of development management (granting or denying permission to develop).

Both are critical roles in ensuring that the public interest is fully served by public spaces, and as much heralded success stories such as Barcelona show (Monclus 2003, p. 417), arguably it is important to get the strategic decision-making framework for public space right before worrying about the detailed execution. This is all the more important given that, globally, more often than not it is the private sector that is actually designing and delivering new public spaces and which is ultimately also often responsible for their on-going stewardship. In such a context, planning is the gateway through which the public interest, as regards the design and management of public space, is tested, and if the opportunity is not taken then to safeguard key qualities and interests, it is unlikely to quickly come again.

At this scale, the London research suggested that three key factors should be considered:

- What are the processes through which public spaces evolve, and how does planning and other forms of regulation interact with them?

- What types of public spaces should be provided, and where?

- How should rights and responsibilities for public spaces be safeguarded over the long term?

These are 'process'-related considerations and re-enforce the argument made elsewhere (Carmona 2014) that it is vital to understand and get the process of design right before focusing on desired outcomes.

\section{Evolving public space (whether formal or informal in nature)}

Public spaces require something in their physical form that allows us to distinguish them from their surroundings as a clear and identifiable place. Typically this is a sense of enclosure, where the buildings and landscape, to greater or lesser degrees, first open up to create a space, and second, wrap around and 'contain' space in order to hold the eye and create a distinct place (Cullen 1961, p. 29). Whilst the factors determining a sense of enclosure are contested 
(Haile 2012), many formal public squares are of this type and planners will need to work closely with developers and other interested parties to ensure they exhibit the sorts of qualities discussed in the second half of this paper.

A strong sense of enclosure is not, however, a prerequisite for a successful public space as increasingly very successful more informal local spaces have been created by simply reclaiming small parcels of street parking or roadway from vehicles, or by paving over the end of a street to create a pause in the urban fabric and an informal space for pedestrians (Fig. 2). Other spaces have been given new character and purpose by the granting of temporary use rights, perhaps for a market, or have even been created as spaces on a temporary or occasional basis through actions as simple as painting markings on a road or repurposing a car park. In this regard, not everywhere needs to be finished and refined, but can also be transient, even rudimentary, in places of regeneration or rapid change (Fig. 3). At the other end of the scale, recent years have also seen the character of many of London's historic squares changing, most notably Trafalgar Square, as a result of traffic calming and significant public realm improvements.

All these sorts of processes will involve distinct planning inputs although they may be initiated outside of the formal planning processes, and most notably from within the highways/street management function of municipalities (Fig. 4). In all cases, planners will need to be flexible enough to understand and embrace the evolving nature of public space, and mindful of the important role of the range of public sector agencies that impact on the shaping of public spaces. In London, for example, four forms of regulation have been critical when creating or re-shaping public spaces:

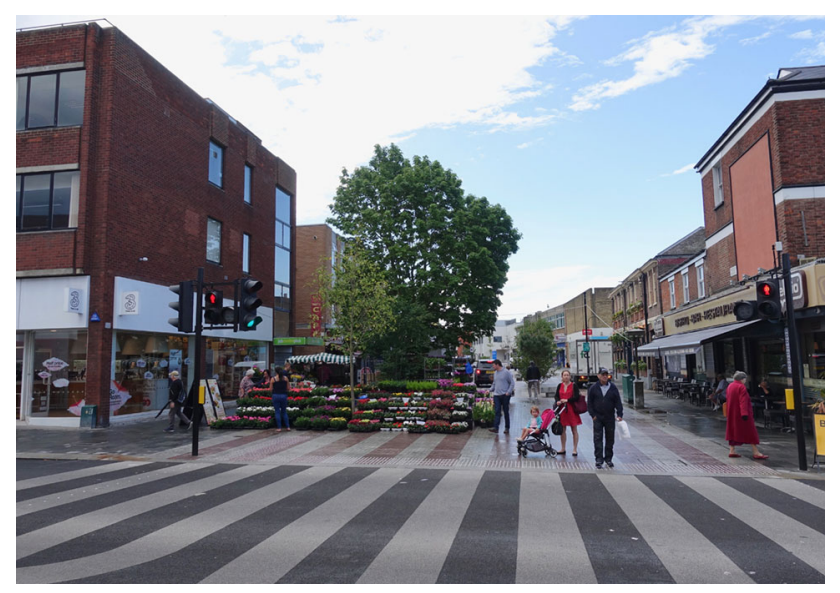

Fig. 2 Passey Place, London-here the end of a side street onto Eltham's busy High Street has been paved over to create an incidental space for shoppers to rest and for informal activities to be hosted

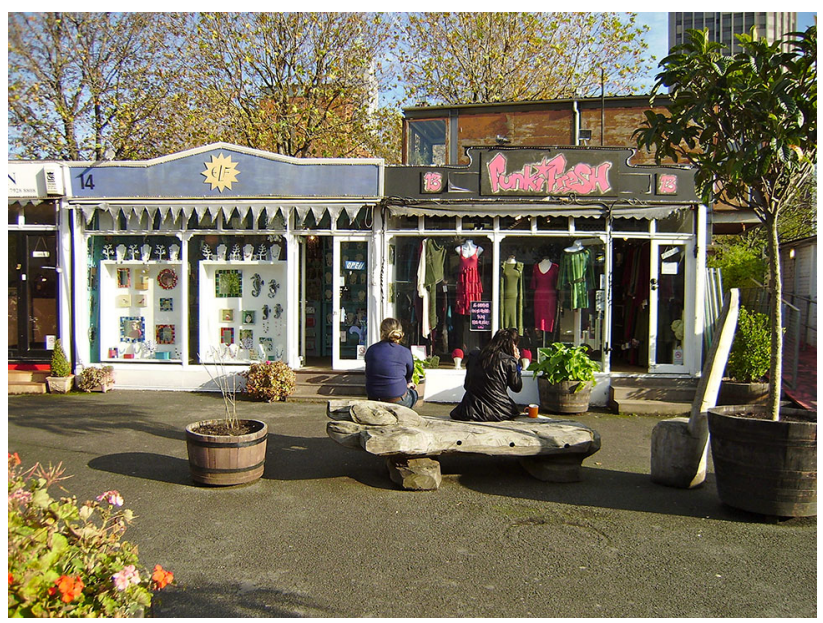

Fig. 3 Gabriel's Wharf, London-was created as a temporary space in 1988, and almost 30 years later is still a favoured meeting and activity place despite its somewhat (and increasingly) shabby appearance

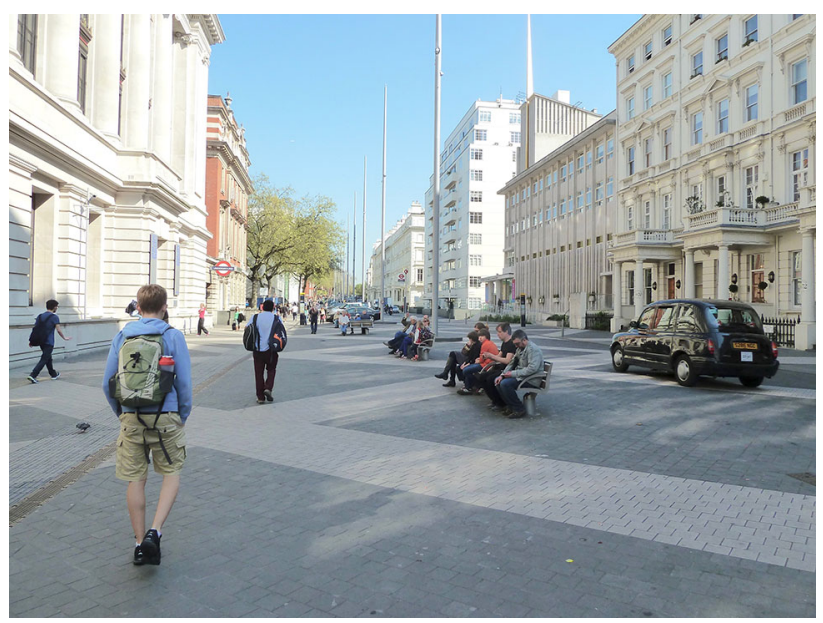

Fig. 4 Exhibition Road, London-here the local authority, the Royal Borough of Kensington and Chelsea, adopted shared space ideas to re-balance the priority given to pedestrians, overlaying the well established street function with a distinct new linear public space function

- Planning controls to sanction new public space proposals or where changes of use or alterations to the (non-highways related) built fabric occur in existing spaces.

- Highways orders, focussing on changes to highways themselves (including 'stopping up' existing rights of way).

- Listed building consents, for changes to the historic (listed) built fabric, a category into which many older public spaces fall.

- Street trading licencing, if proposals involve uses concerned with selling goods or services in public space. 
Planning therefore also has a vital coordinating function across the various actors in order to ensure that policies and approaches are in harmony and outcomes, including innovations in practice, are optimised.

\section{Diverse public space (avoiding one-size-fits-all)}

The principle of cities, and by extension public spaces, for all has been fundamental to many discussions about the city at least as far back as Henri Lefebvrre's (1968) call for a right to the city. But if one accepts that the city is for all and certain unalienable rights need to be guaranteed for everyone (Habitat International Coalition 1995), then it also follows that the city will be one of diversity and difference, and not everyone will seek the same or even compatible things. Consequently not every public space will, or should, cater equally to every citizen or for every occasion, despite calls in some quarters that anything less is in effect exclusion (e.g. Malone 2002). Indeed, the London research confirmed that public spaces take on different flavours as a result of the different groups of interests that create them and the particular range of uses they accommodate. It follows that just like rooms in a house or buildings in a city, it would be foolish to try and design all public spaces according to some idealised cloned blueprint in order that each is equally appealing to all. Some spaces are vibrant and commercial, others focussed around play (for children and/or adults-Fig. 5), others are serious and civic, or peaceful and relaxing (Fig. 6).

This diversity recognises the diversity of lifestyles, preferences and needs amongst urban populations and that through the design of their public realm there is the opportunity for urban areas to offer something for everyone

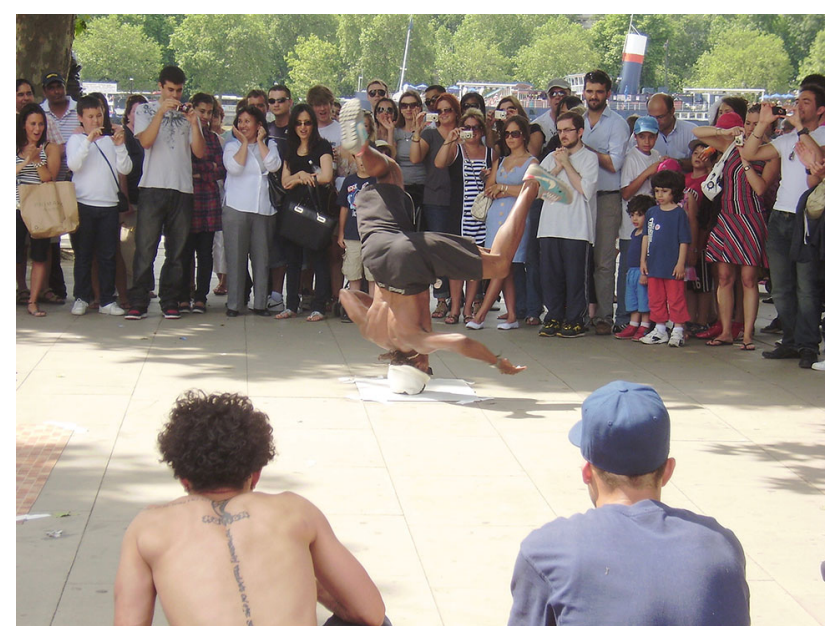

Fig. 5 Southbank, London - the sequence of spaces along the south bank of the Thames in central London have been transformed in recent years and now host a variety of 'fun' activities from public art, to performance, to consumption

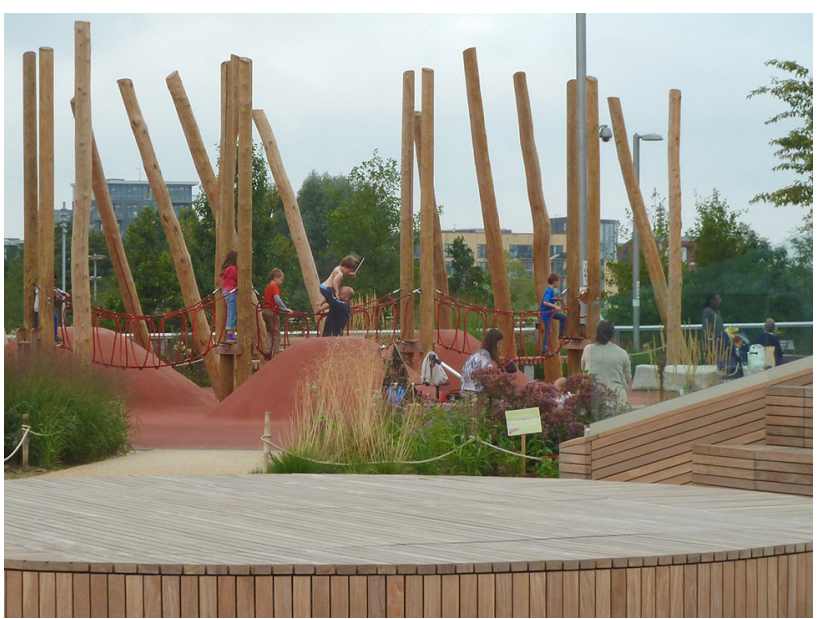

Fig. 6 Queen Elisabeth Olympic Park, London-the new spaces of Queen Elisabeth Olympic Park are varied in themselves but range from raucous play spaces to quiet areas for peaceful relaxation

in the right locations although not necessarily everything for all everywhere. It is important for planners to recognise this legitimate diversity, particularly in large cities, and to avoid imposing one-size-fits-all aspirations on public space projects that play into critiques around the homogenisation of public space (e.g. Light and Smith 1998; Sennett 1990). In this respect, the public spaces of a town or city can be planned in a strategic sense just as the buildings are, with care taken to ensure that all sections of the community are catered for, and that spaces are provided in locations that are safe, convenient and inviting to use and that avoid conflict, for example, between skateboarders and commercial interests or between revellers and residents.

But whilst strategic planning for green spaces has long been on the agenda and is widespread (e.g. CABE 2004b), the notion of planning in a more systematic fashion for public spaces more generally has not been widespread and only a minority of cities such as Copenhagen and Melbourne can claim to do so. If the London experience is indicative of the situation elsewhere, then at the heart of such efforts should be planning for a diversity of provision and not just for a greater quantum of public space, and certainly not for an over-simplified and potentially homogenised vision of one-size-fits-all (Fig. 7).

\section{Free public space (securing rights and responsibilities)}

The discussions about our rights to the city often focus on who owns and manages space, with the most polemical discourses denouncing processes of privatisation as the death of public space (e.g. Mitchell 1995). Empirical research, by contrast, has tended to show that ultimately the rights and responsibilities associated with spaces and what 


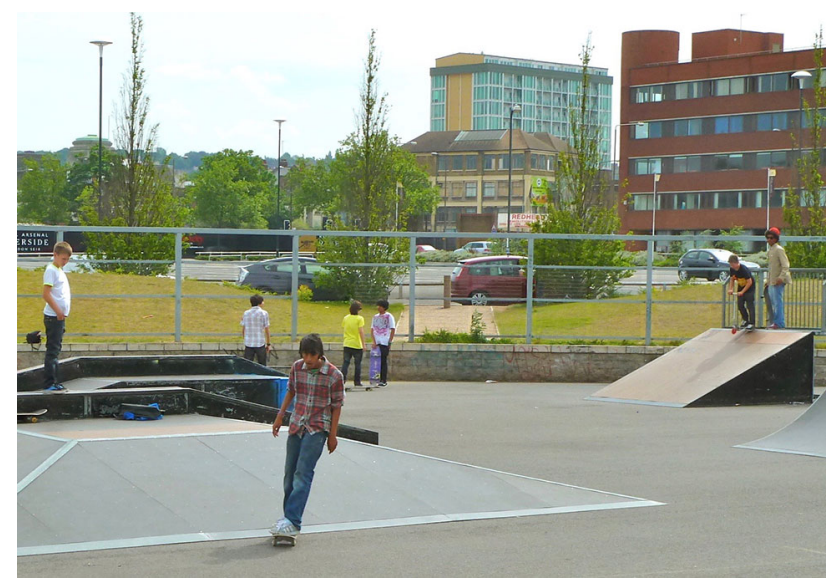

Fig. 7 Woolwich skatepark, London-this skatepark southeast London caters to a specific and largely youthful audience who appropriated an otherwise underutilised public space on the edge of the town and encouraged the local authority to invest in it as a dedicated space to meet their needs

this implies about how public they are is more important than who owns and manages them (Carmona et al. 2008, p. 80). In fact, public spaces are owned and managed through multiple complex arrangements, and always have been, and many are neither clearly public or private as regards who owns and manages them (Fig. 8). Moreover, restrictions on use apply to all spaces, regardless of ownership, not least as a means to ensure that their amenity value is distributed fairly across the range of potential users (Nemeth 2012, p. 21). Yet underpinning the notion of 'public' space in much of the literature is the idea that, as far as possible, space should be 'free', in three senses of the word: open, unrestricted and gratis. Arguably, whatever the

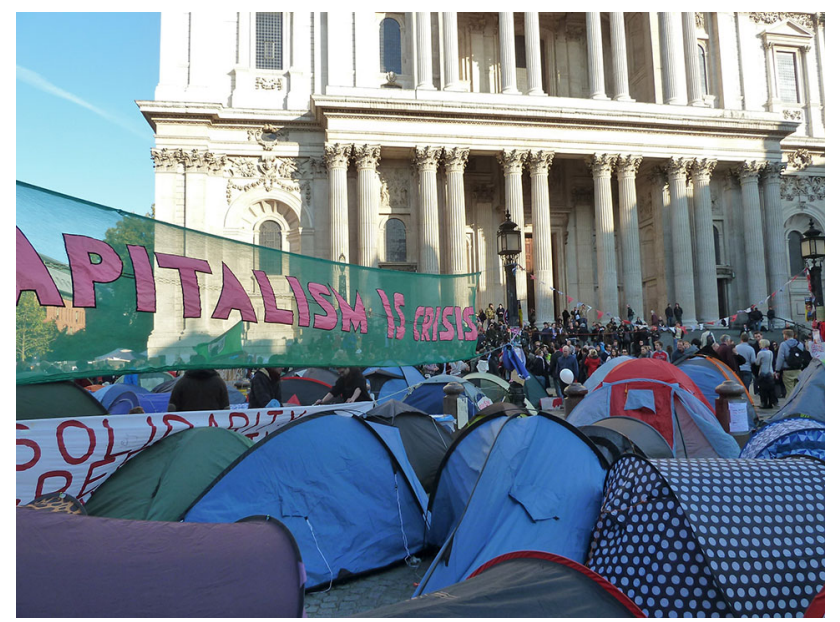

Fig. 8 St Pauls Churchyard, London-spaces surrounding St Paul's Cathedral are in a range of ownerships, including this one, site of the 2012 Occupy encampment, which is owned by the Church of England, although managed by the City of London and is an open and fully accessible part of the local street network ownership, such guaranteed freedoms of use are best established through clearly setting out guaranteed rights and responsibilities for users and owners alike at the time that spaces are created or regenerated.

This does not always happen, and particular problems occur when owners and managers seek to use the privilege of ownership to exclude key groups (such as teenagers), restrict access (for example, at night) or impose codes of behaviour that go beyond societal norms such as the banning photography (Fig. 9). Whilst, in common with many cities, these sorts of behaviours are not widespread in London, when they occur they undermine the freedoms that public spaces users rightfully expect. For planners, it is therefore vital to negotiate these long-term management issues at the same time as more immediate quality concerns are considered. If rights and responsibilities are not tied down at the time that regulatory permissions are given, it will be much harder to revisit them later. Municipalities, for example, might consider adopting a Charter for Public Space Rights and Responsibilities in policy or ordinance as a standard set of expectations that would relate to all public space proposals (Fig. 10).

\section{Designing public spaces}

Beyond strategic considerations relating to how public spaces evolve and are regulated, the balance of space types across an urban area, and how to guarantee rights and responsibilities; at a more detailed level, planners are also often the guardians of how new public spaces are created and existing spaces are regenerated. Thus through their plans, ordinances, frameworks and policies, or through

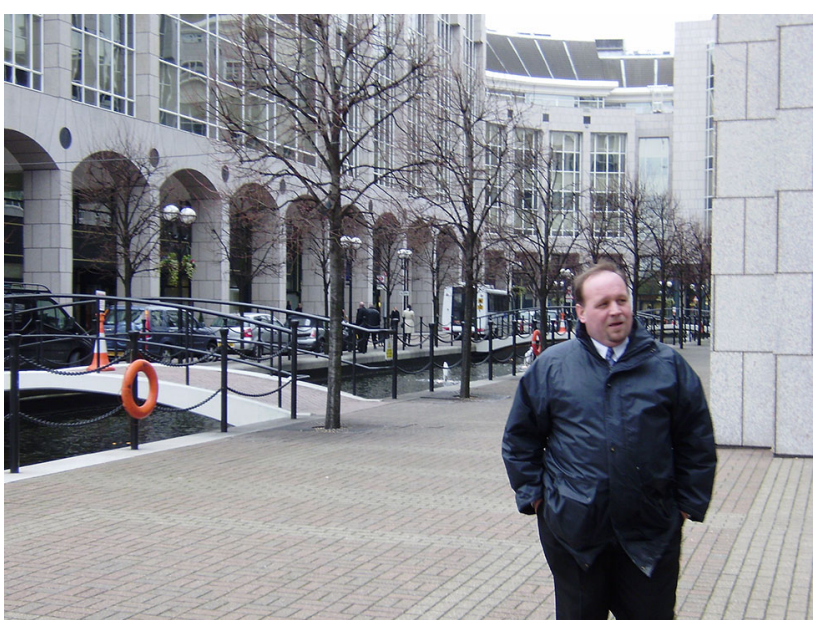

Fig. 9 Mulberry Place, London - the author being asked by private security to desist from taking photographs outside the Town Hall of the London Borough of Tower Hamlets, part of a private estate in Blackwall 
Fig. 10 An indicative charter for public space rights and responsibilities

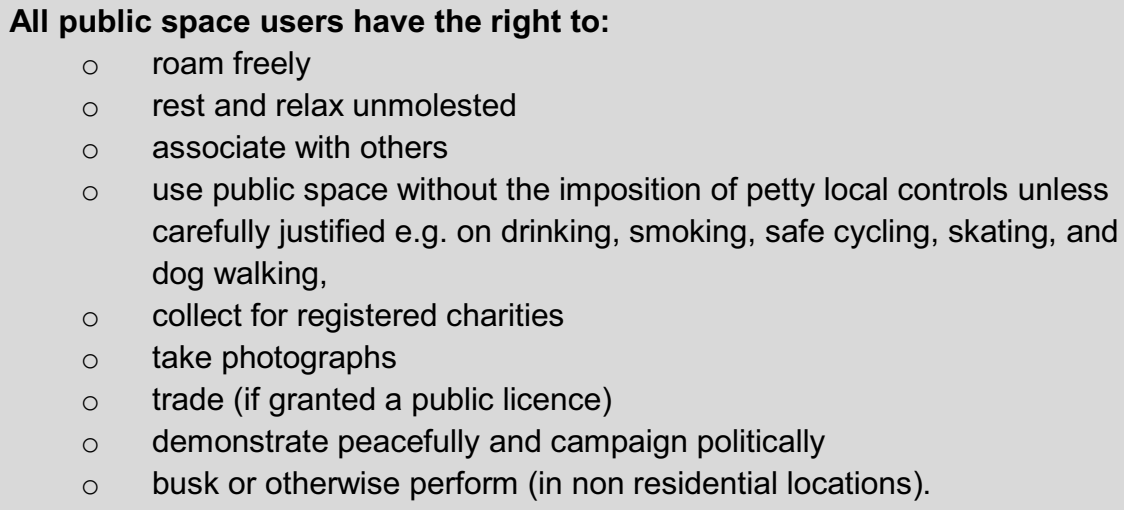

Public space users have a responsibility to:

- respect the rights of others to conduct their business unhindered and unmolested

- respect public and private property

- act in a civil and safe manner at all times

- avoid littering

- keep the peace.

\section{Owners and managers of public space have a responsibility to:}

- respect and protect the rights of all users, including to privacy

- treat all users in an equitable and inclusive manner

- keep spaces safe within the context of the actions of any reasonable person

- keep spaces clean and well maintained

- keep spaces open and unrestricted at all times (or otherwise in line with regulatory stipulations). discretionary negotiations on development proposals during the regulatory process, planners have the opportunity to set out and implement clear principles for the sorts of public spaces they would wish to see. Whilst every public space will be different, and attempts to define universally applicable principles for 'good' public space design are often based on little more than supposition and intuitive analysis (e.g. UN Habitat 2013), extensive empirical testing revealed a number of critical factors that are likely to be important in the design of most public spaces (Carmona and Wunderlich 2012). These concern

- How public spaces are clearly delineated from private ones so that they feel and are publically accessible.

- How the uses surrounding public spaces contribute to creating engaging places for users.

- How spaces can be made more meaningful through the amenities and features they host.

- How the opportunity is taken to maximise the potential for a positive social environment in public space.

- How a balance between vehicles, pedestrians and other users in public space is set and safeguarded.
- How spaces are made to feel comfortable through their ability to foster safe and relaxing use.

- How robust public spaces can be created as a consequence of their ability to adapt to changing demands across time whilst remaining distinctive.

The remainder of this paper takes these seven factors in turn and, drawing from the research, suggests in a little more detail why they are important and, in relation to each, which aspects planners might consider.

\section{Delineated public space (clearly public in their use)}

The problems associated with creating spaces that are neither clearly public nor private in their use have been well documented in the urban design literature, at least since the writings of Oscar Newman (1973). This has long been a problem in residential areas, but is also apparent in some commercial developments (Fig. 11), whilst some retail schemes can appear overly exclusive and therefore not fully public, or at least not welcoming to all. There remains an important need to carefully delineate the public 


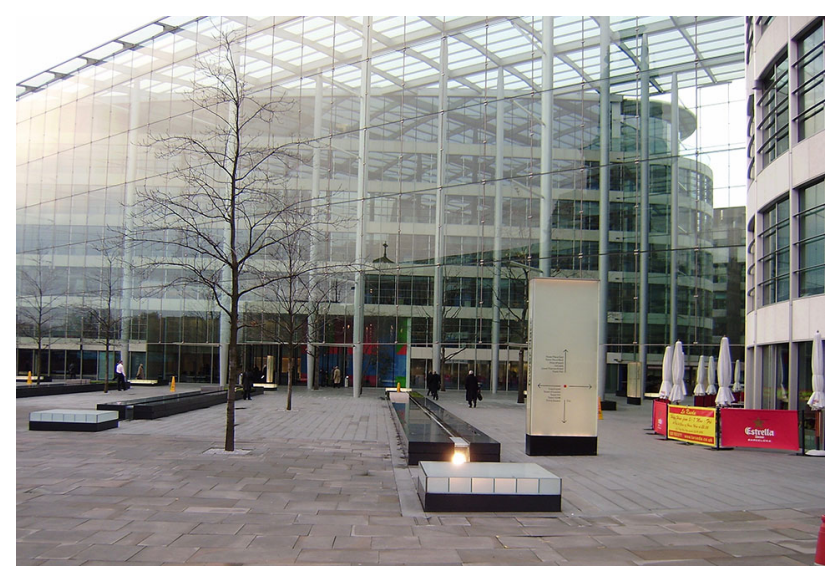

Fig. 11 Tower Place, London-here a new public space extends from between the two new buildings of the development and out into an open area alongside All Hallows-by-the-Tower Church. The presence of a glazed roof over part of this space, the obvious corporate nature of the buildings and the heavy presence of security guards undermines the sense of this being a public space and as a result it is not clear whether the general public are allowed into the space or not

and private realms of the city, recognising that public spaces in the wrong places can be more problematic than the absence of public space altogether (Fig. 12). Instead, public spaces (including all varieties of pseudo-public space) should be designed to appear welcoming, inviting and visually and physically accessible, avoiding any doubt in users' minds that they are clearly public, regardless of who owns and manages them. Equally, private spaces for relaxation such as private or communal gardens have an important and quite distinct role that is separate from the

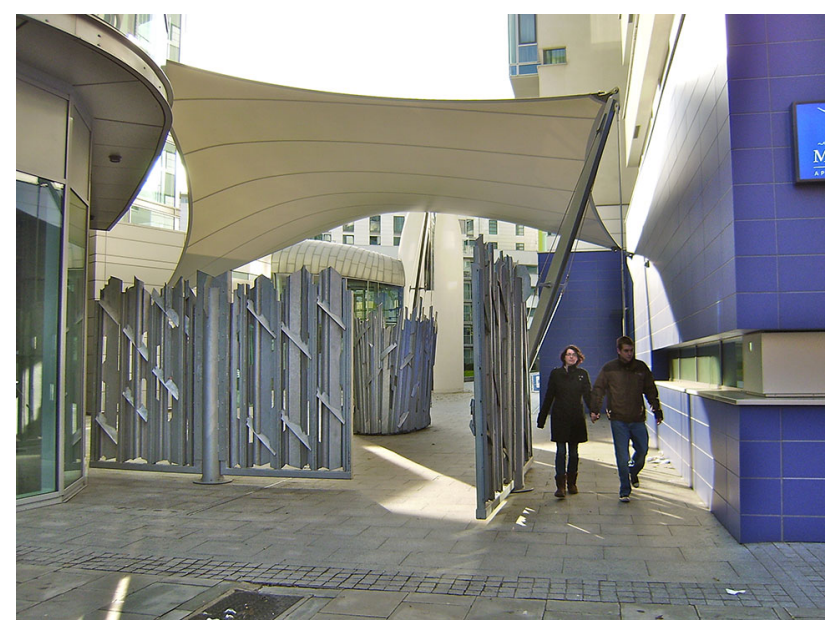

Fig. 12 Empire Square, London-a new public square was required by the planners in the middle of a residential block, but gated on the advice of the Metropolitan Police so that it could be closed at night in order to minimise resident/user conflicts. This has resulted in poor visual permeability and a less than clear status shared public parts of the city. Through the way they are designed, these parts of the city should be clearly private, even if visible from the public realm. This is not segregation in the negative sense that it is sometimes viewed as in the literature (e.g. Webster 2001), but merely a positive division between the public and private functions of the city; the careful demarcation between which represents a fundamental quality of good urbanism (Carmona et al. 2010, p. 219).

\section{Engaging public space (designing in active uses)}

Whilst buildings, landscape and infrastructure define the physical limits of external public spaces, the land uses surrounding spaces, and those lining the streets leading from spaces, will dictate what sort of places they will be; whether peaceful, gently animated or full of life. At all times it is important to be realistic about what will work and what will not in particular locations, and therefore about what sort of space can or cannot be created. Trying to create a vibrant commercial hub in a quiet residential area (Fig. 13) or a peaceful oasis in a busy urban centre is likely to be unrealistic.

Despite criticisms that public spaces have become overcommercialised and unduly dominated by the pressure to consume (e.g. Hajer and Reijndorp 2001), much of the buzz associated with particularly active spaces will tend to be wrapped up in the activities of consumption of one sort or another-shops, cafes, bars, markets, etc.-and typically these processes animate and enrich public spaces and are welcomed by users (Fig. 14). If the intention is to create such a space then active uses should be carefully designed into the public space from the start, helping to fill them

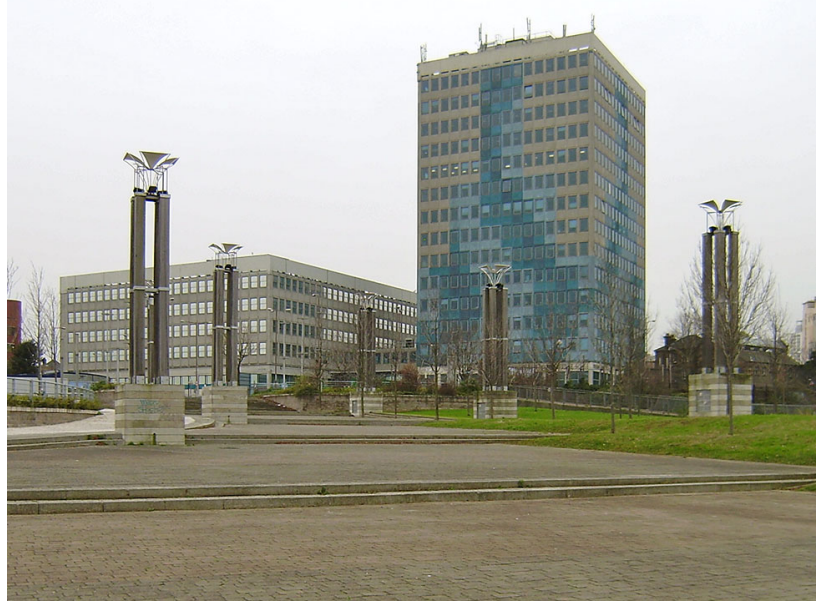

Fig. 13 Royal Arsenal Gardens, London-this new square on the edge of Woolwich in south east London was created at great expense to connect the town to the River Thames, but remained a largely deserted and often foreboding space when the proposed developments around it failed to materialise leaving the space without a purpose 
Fig. 14 Bermondsey Square, London-this new square in a very diverse part of south London houses a farmers market, an antiques market, and an array of informal activities (including table tennis).

Opening onto it is a supermarket, a hotel, a café, a number of small shops and a large number of apartments

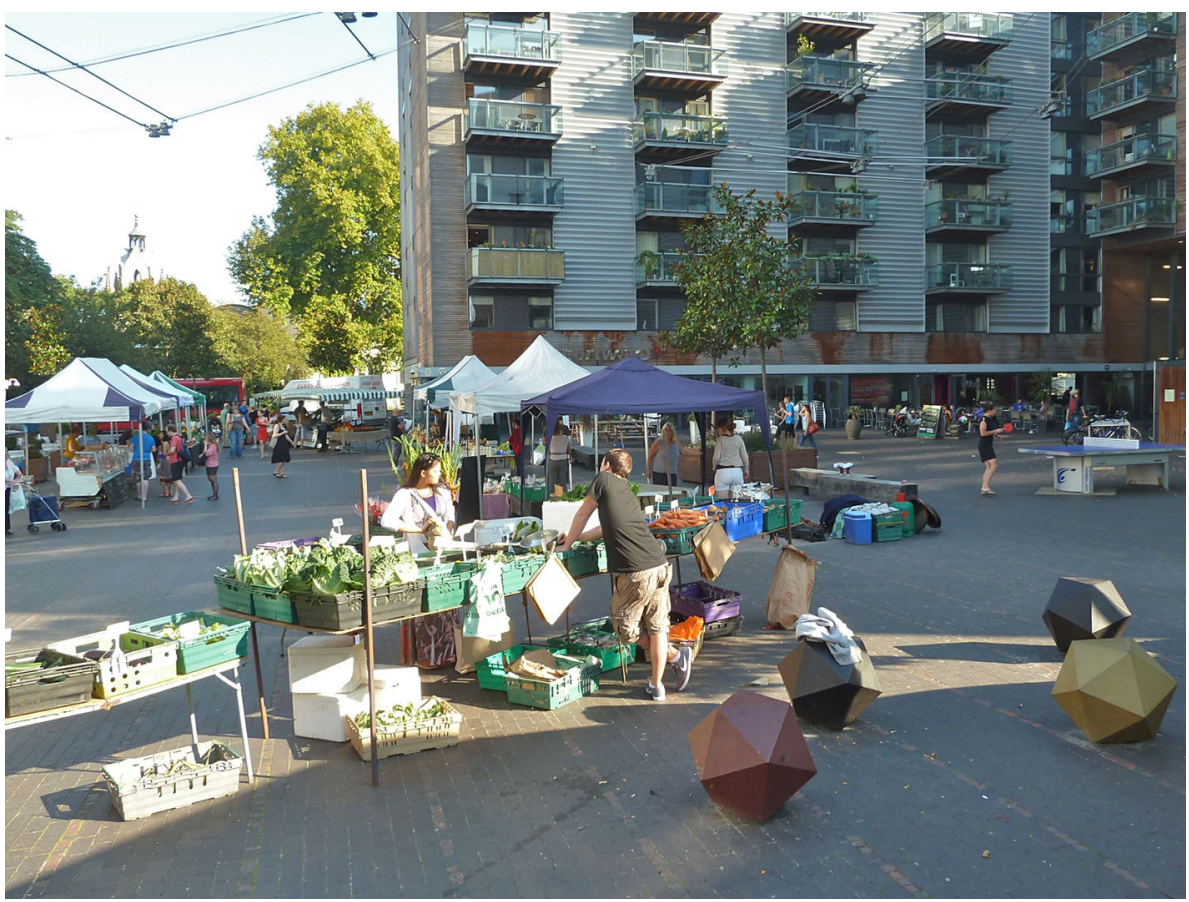

with life and allowing users to engage with them. The importance of getting the use mix surrounding (and within) public spaces right is therefore an early and critical lesson in the public space design process and involves decisions in which planners almost always play a leading role.

\section{Meaningful public space (incorporating notable amenities and features)}

Extensive interviews with users of spaces across London suggested that they are primarily concerned with how they experience space-good or bad, engaging or repellent, attractive or ugly-rather than with narrow stylistic concerns associated with the details of their design or whether they are narrowly 'authentic' or not; a concern of some of the public spaces literature (e.g. New Economics Foundation 2004). Over time, spaces become more meaningful as users interact with them and they acquire the patina of age and use. Spaces can also become more meaningful by incorporating key historic or landscape features (e.g. existing historic buildings or mature trees-Fig. 15), and by hosting other amenities and features with which users can directly engage (Fig. 16). These might be active, such as big screens, band stands, kiosks, sports facilities, fountains, paddling pools, play equipment, skating opportunities, stages, amphitheatres, lighting displays and so forth. Equally they may be restful, serious or contemplative, such as public art, sculptural furniture, memorials and monuments, reflection pools, flower gardens/displays, wifi hot spots, and so on.

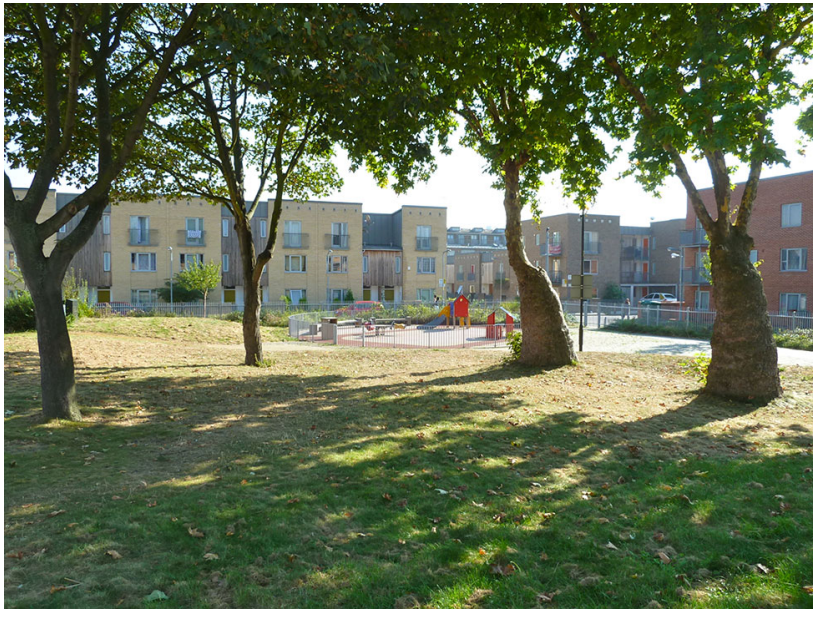

Fig. 15 Angel Town, London-here the trees have seen the social housing around them knocked down and rebuilt twice, and stand as a sign of continuity and nature

\section{Social public space (encouraging social engagement)}

How we design public spaces can make them more or less conducive to social interactions of all types, from largescale events and festivities, to low key humble encounters, and everything in-between. Rather than a retreat from public space as predicted by some (e.g. Graham and Marvin 2001), the evidence from London suggested that, if conducive to such uses, public spaces still represent the definitive venues for public debate, protest, encounter, collective experience, communication and the rich and varied social life of towns and cities. Detailed 


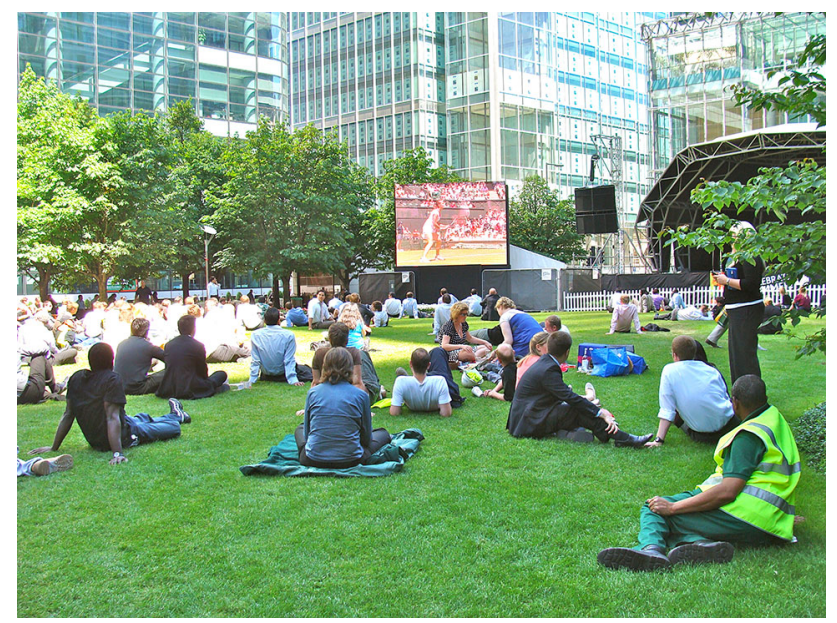

Fig. 16 Canada Square, London-is heavily used throughout the year for large-scale events and for everyday relaxation and social engagement. A big screen is a popular lunch time and after work entertainment for the workers of Canary Wharf

observational work revealed that movement in public space predominantly flows along dominant movement corridors or 'desire lines' passing right through spaces, and from movement corridors to the active uses on a space and vice versa. In the majority of spaces that are well integrated into the movement network, only a small proportion of users will actually stop within and engage directly with the space itself whilst the majority will pass straight through. Nevertheless, high levels of through movement will generally stimulate high levels of activity on the space, with the highest density of such activities (and social encounters) typically occurring in the gaps between the dominant lines of movement and being drawn to and around key amenities and features (Fig. 17).

Individual spaces (if large enough) can also work successfully as a series of distinct and separate subspaces, each with a different character and purpose and designed to attract different sorts of users (e.g. fountains for children, steps and ramps for skateboarders, alcoves for quiet conversation, and so forth) (Fig. 18). In designing public space, it is as important to consider the desired social outcomes and how the physical space and its context will or will not support them. Whilst particular social outcomes can never be guaranteed (Carmona et al. 2010, p. 133), leaving such outcomes entirely to chance is unlikely to be a successful strategy.

\section{Balanced public space (between traffic and pedestrians)}

The challenge of traffic dominance is a perennial problem that continues to blight many public spaces with severe knock-on impacts on their social life (Gehl and Gemzoe

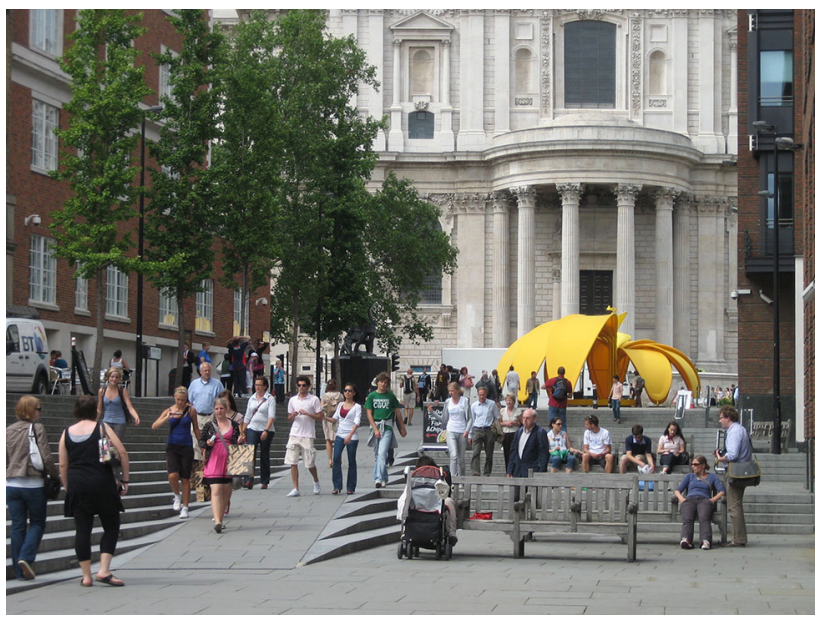

Fig. 17 Peter's Hill, London-here the dominant movement corridor through the space is very strong from St Pauls Cathedral to the River Thames, but space is provided in quieter areas for those who wish to stop and relax

2000). The solution, however, does not have to be banning all traffic. Instead, a subtle re-balancing of space is often all that is required as traffic and pedestrians can harmoniously share public space with mutual benefits to both groups: allowing drivers direct access to and between important urban centres; and providing a background level of animation and surveillance in public spaces. This requires that enough space is given to pedestrians for movement and socialisation; that they are not corralled and kettled (Fig. 19) but trusted to move and navigate freely; and, to enable this, that traffic is slowed sufficiently on roads leading into and through public spaces (Fig. 20).

\section{Comfortable public space (feeling safe and relaxing)}

Despite claims in the literature that there has been a general securitisation of public space (e.g. Minton 2009), in reality, security is expensive and arrangements tend to be pragmatically defined to reflect the needs of different types of public spaces. Whilst some very busy spaces (e.g. the forecourts of major railway stations) may need and do possess highly visible security (Fig. 21), most do not. Ultimately, the objective should be the wellbeing and sense of wellbeing of users, and their ability to use spaces in a relaxed and comfortable manner.

Interviews with the users of public spaces in London confirmed the long-held view from Jane Jacobs (1961) onwards that security (or at least a sense of security) is first and foremost determined by how busy spaces are, as active spaces will always seem safer than deserted ones, as will spaces that are well overlooked and clearly visible from the outside. Second, how well spaces are managed also has an impact, with spaces that are clean and tidy and well 


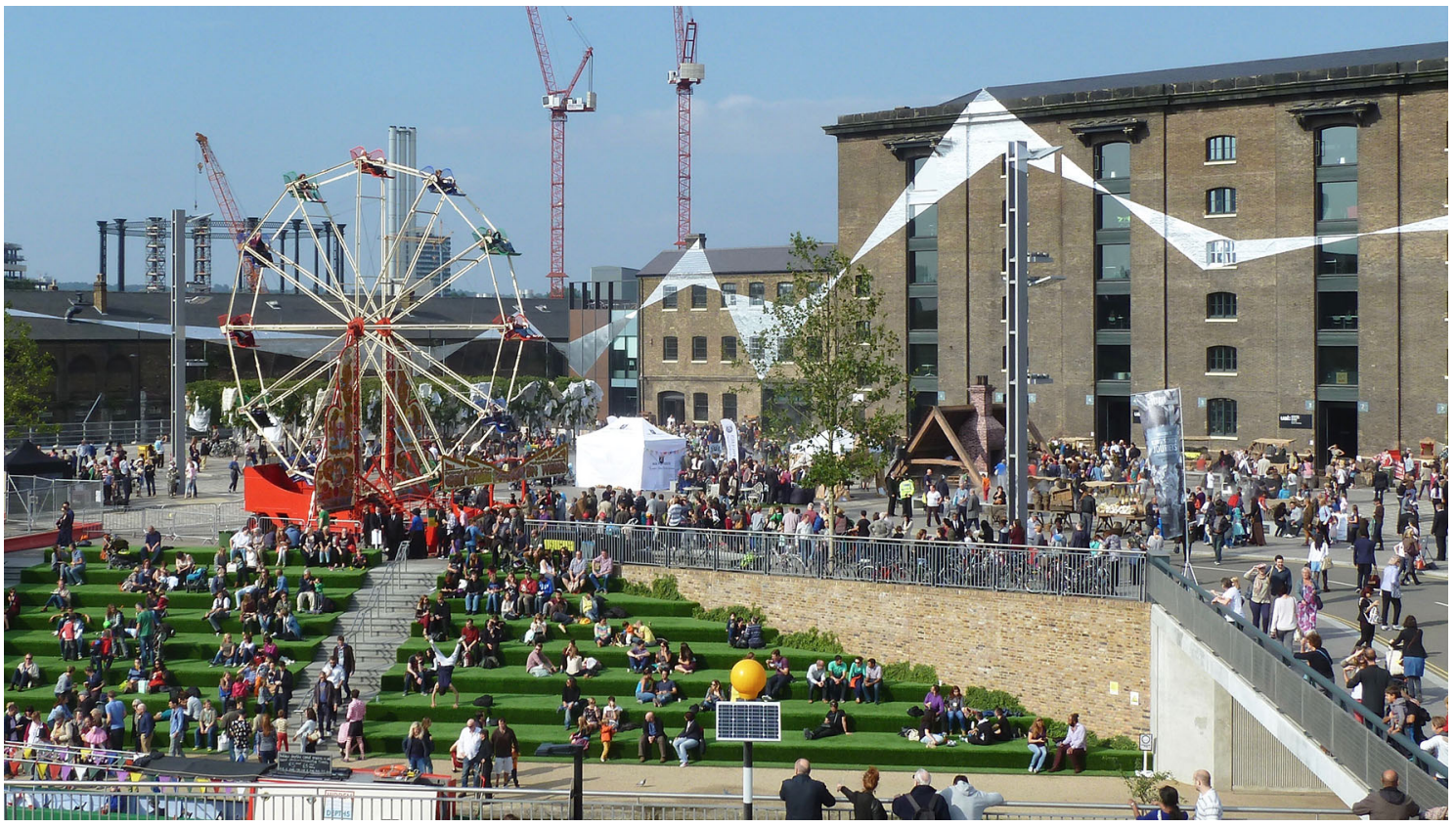

Fig. 18 Granary Square, London - the public space at the heart of the Kings Cross Railway Lands redevelopment incorporates a range of new subspaces, including onto the Regent's Canal and setting off the

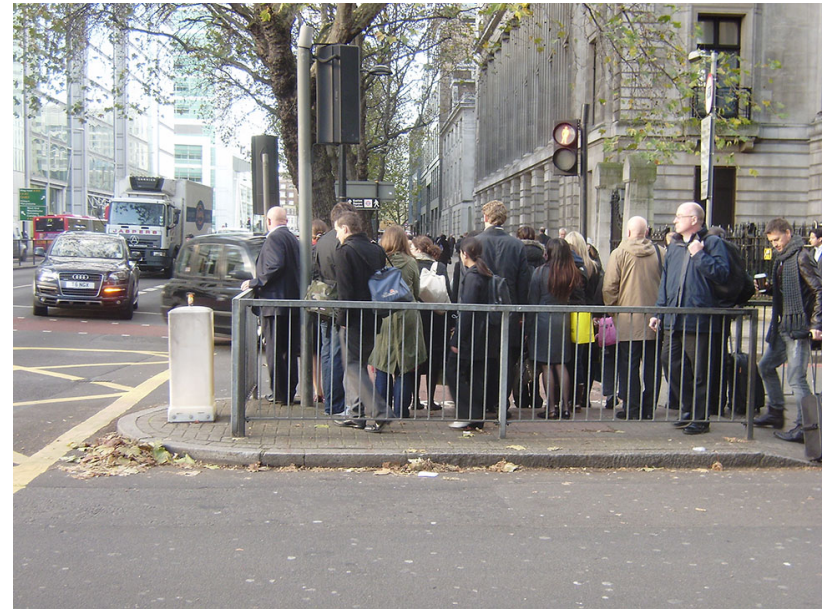

Fig. 19 Euston Road, London-barriers corralling the pedestrians are still a common site across London, although are gradually being removed (as they have been here) in favour of allowing pedestrians to make their own decisions about where, how and when to move

maintained generally feeling safer than those that are not. Finally, spaces should be relaxing, with opportunities to stop and linger, for example, with good quality, comfortable and preferably moveable formal seating, informal seating opportunities (on steps, kerbs and walls), toilet facilities, soft landscaping and careful consideration given to microclimate (places to sit in the sun, and to shelter from the wind and the rain). Grass, for example, whilst requiring active maintenance, is very popular because it is buildings of the historic Goods Yard where steam jets, fountains and lighting effects help animate the space

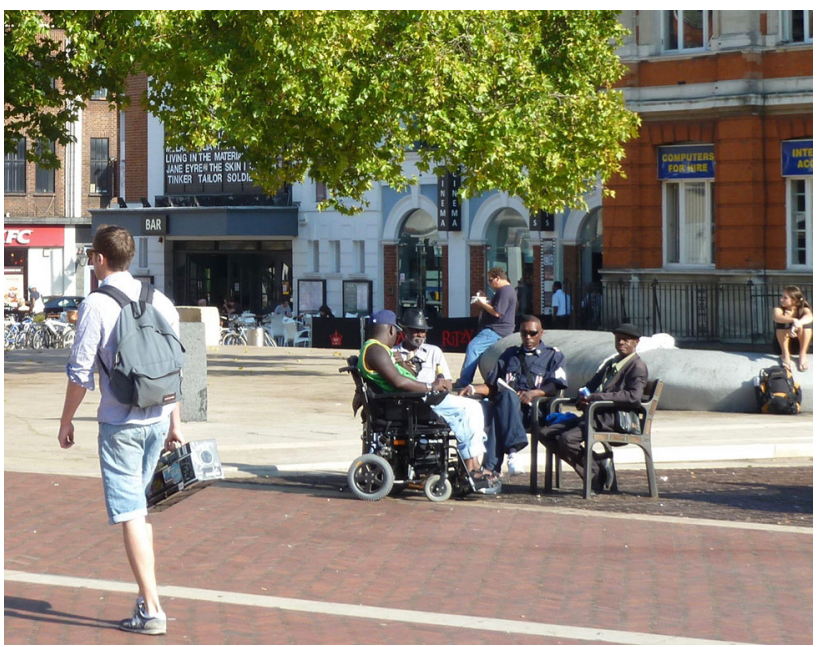

Fig. 20 Windrush Square, London-this new incidental space reclaims part of the road carriageway to establish an important new hub for the multi-cultural social life of Brixton

comfortable, flexible and allows users to position themselves to take advantage of micro-climatic conditions. It is also highly conducive to relaxation, play and social engagement (Fig. 22).

\section{Robust public space (adaptable and distinct in the face of change)}

Finally, the success of public spaces will depend on shaping places which, through their robust design (simple, 


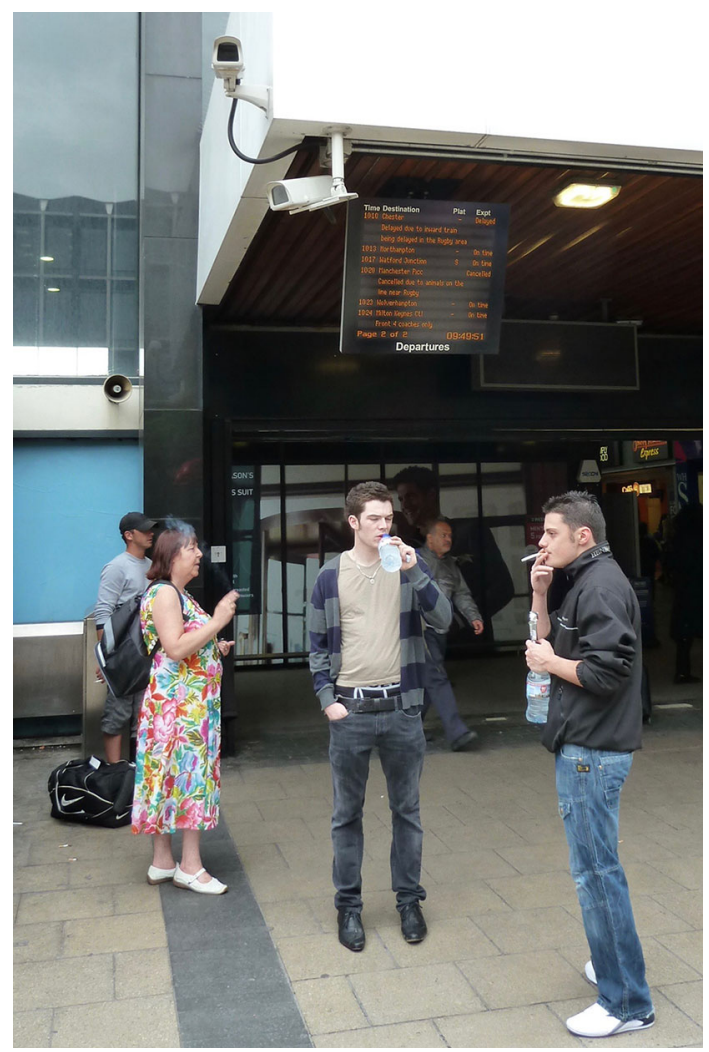

Fig. 21 Euston Station Piazza, London: smokers outside Euston station being watched over by prominent CCTV and often by a heavy police presence

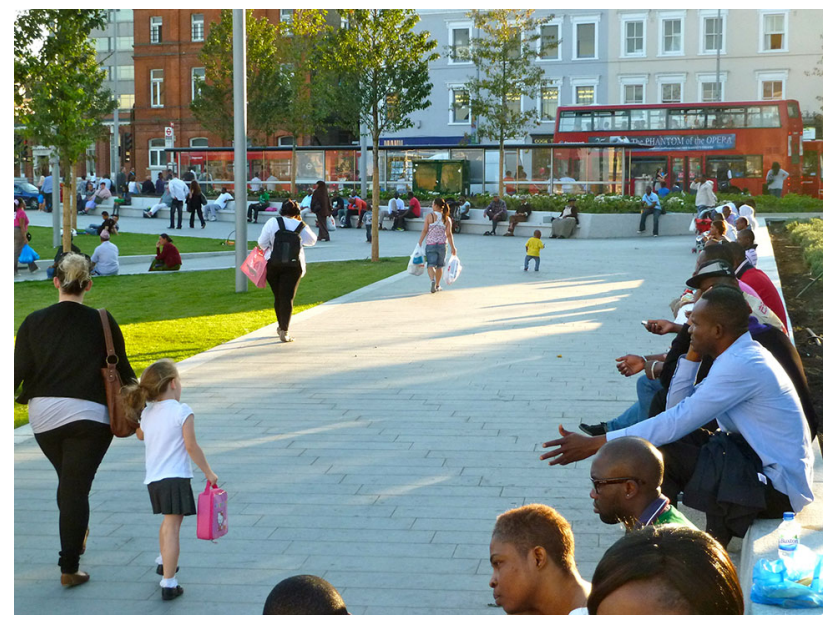

Fig. 22 General Gordon Square, London-the complete redesign of this space has transformed it from a sad and largely abandoned space into an active hub of life for the ethnically and economically diverse communities that live in Woolwich. In the summer it fills with people who sit, lounge and play on and around the grass and (sometimes) watch the big screen

uncluttered and with resilient natural materials, trees and planting), and background level of activity, are able to adapt and change over time in a manner that can withstand the sorts of homogenisation pressures that are so derided in the literature (e.g. Boyer 1993) and which still feel distinct, welcoming and rooted in the local context. In the short term, this means spaces that can adapt to different uses and activities, perhaps at different times of the day (somewhere for workers to lunch or for children to play-Fig. 23), throughout the week (a market on a Monday and, without feeling deserted, peace and quiet on a Sunday), or across the year (concerts in the summer and ice skating in the winter-Fig. 24a and b). In the long term, it will mean successfully adapting to changes in the uses that surround the space or to the demands placed on spaces by changes (yet unknown) to society and technology. It will also mean design solutions that reflect the realities of management routines and the budgets available for the upkeep of public space, with materials and features that are able to age gracefully and in a timeless manner.

\section{Conclusions}

Normative frameworks for urban design have often been much criticised for the tendency they encourage in us to focus on a narrow view of defined physical outcomes in the absence of a proper understanding of their socio-political context (Sorkin 2009, p. 181; Bidduph 2012; Arabindoo 2014, p. 48). Whilst this must be a danger and uncritical application of any design prescriptions in policy or projects should be avoided, we should not be so weary that we are prevented from articulating the results of well-grounded research and analysis in normative terms as this paper has attempted to do.

Arguably, the issue is not normative prescription per se, but the caution (or absence of caution) with which prescriptions are applied. So, beginning with this heavy caveat and with the proviso that all the research underpinning the normative principles described in this paper was derived from analysis of London (as the illustrations throughout have reinforced), it is postulated that the ideas espoused provide a straight-forward and widely applicable framework against which planners and other regulators can assess their own engagement with issues of public space design and management. On this basis successful public spaces are

1. Evolving (whether formal or informal in nature).

2. Diverse (avoiding one-size-fits-all).

3. Free (with secure rights and responsibilities).

4. Delineated (clearly public in their use).

5. Engaging (designing in active uses).

6. Meaningful (incorporating notable amenities and features).

7. Social (encouraging social engagement).

8. Balanced (between traffic and pedestrians). 
Fig. 23 Swiss Cottage Community Square, Londonthis large new space is highly popular and adaptable, allowing for relaxation and play throughout the day by a range of user groups

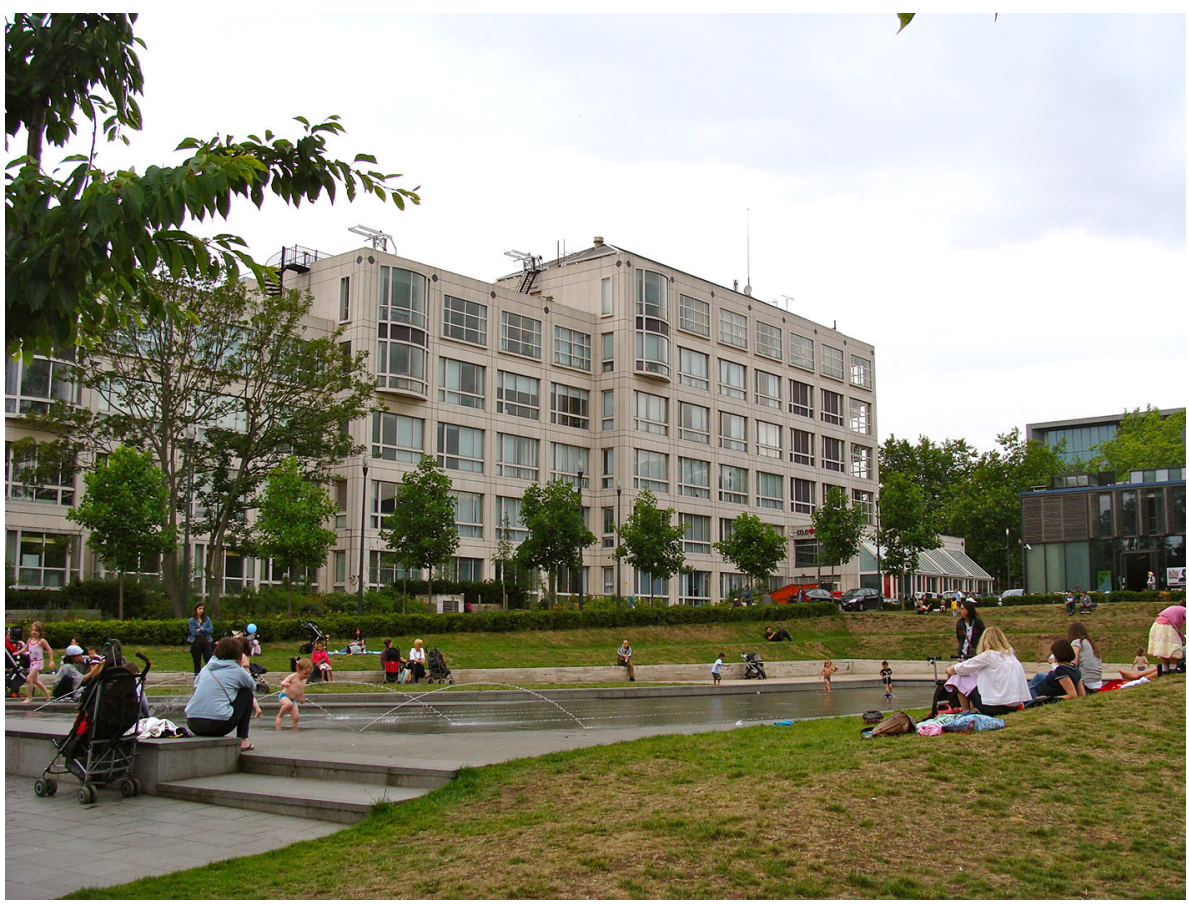

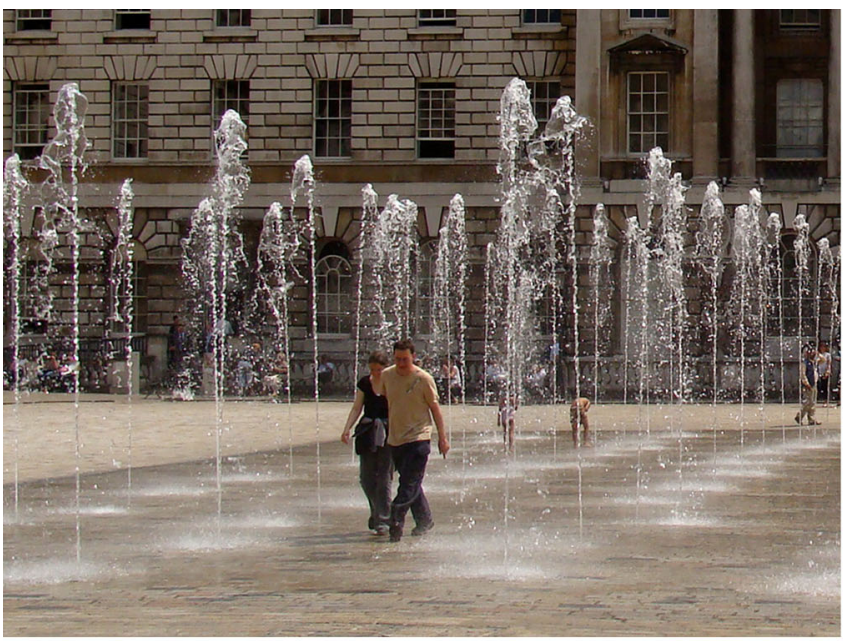

(a)

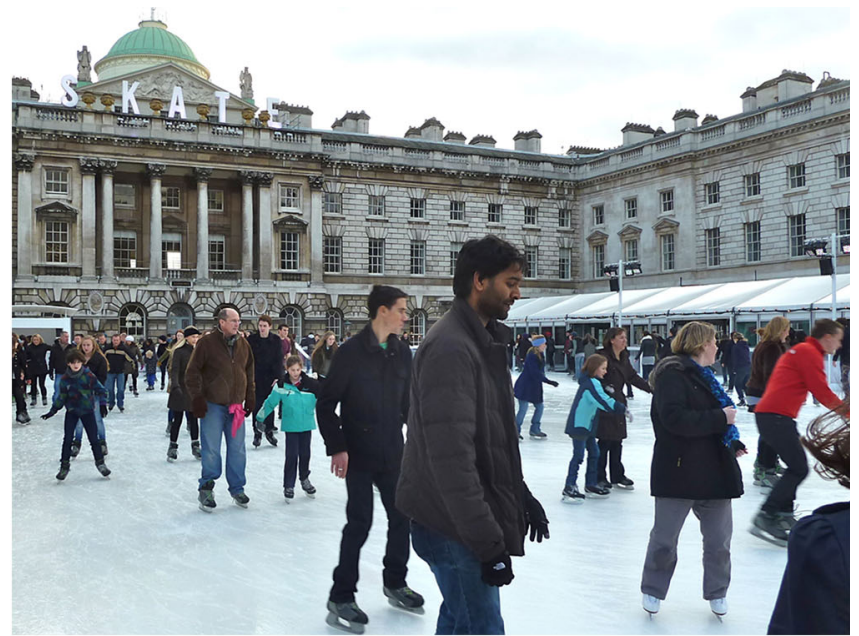

(b)

Figs. 24 Somerset House Courtyard, London - this space, managed by a charitable trust, is used heavily throughout the year, but is particularly popular for its fountains in the summer (a) and ice skating in the winter (b)

9. Comfortable (feeling safe and relaxing).

10. Robust (adaptable and distinct in the face of change).

As the recent UN Habitat (2013) report on streets and public spaces as drivers of prosperity reminds us, these are universal concerns of equal or perhaps even greater significance to the cities of the global south than to already rich and highly developed cities such as London. Such issues are too important to be left to chance or to ad hoc case by case negotiation on individual projects and propositions. Instead, as has been argued, in advance of development there is huge value in setting out a series of well-grounded positive principles for public space design, set within a coherent strategic framework for the long-term planning and management of public spaces. This paper has attempted to show how.

Open Access This article is distributed under the terms of the Creative Commons Attribution 4.0 International License (http://crea tivecommons.org/licenses/by/4.0/), which permits unrestricted use, distribution, and reproduction in any medium, provided you give appropriate credit to the original author(s) and the source, provide a 
link to the Creative Commons license, and indicate if changes were made.

\section{References}

Arabindoo, P. 2014. Urban Design in the Realm of Urban Studies. In Explorations in Urban Design, ed. M. Carmona. London: Ashgate.

Bidduph, M. 2012. The Problem with Thinking About or for Urban Design. Journal of Urban Design 17 (1): 1-20.

Boyer, M. 1993. The City of Illusion: New York's Public Places. In The Restless Urban Landscape, ed. P. Knox. New Jersey: Prentice Hall.

Carmona, M. 2014. The Place-Shaping Continuum: A Theory of Urban Design Process. Journal of Urban Design 19 (1): 2-36.

Carmona, M. 2015. Re-theorising Contemporary Public Space: A New Narrative and a New Normative. Journal of Urbanism 8 (4): 374-405.

Carmona, M., and F. Wunderlich. 2012. Capital Spaces, the Multiple Complex Public Spaces of a Global City. London: Routledge.

Carmona, M., C. de Magalhaes, and L. Hammond. 2008. Public Space. London: The Management Dimension.

Carmona, M., S. Tiesdell, T. Heath, and T. Oc. 2010. Public Places Urban Spaces, The Dimensions of Urban Design, 2nd edn. London: Routledge.

Corbett, N. 2004. Transforming Cities, Revival in the Square. London: RIBA.

Commission for Architecture and the Built Environment. 2004a. The Value of Public Space, How High Quality Parks and Public Spaces Create Economic, Social and Environmental Value. London: CABE Space.

Commission for Architecture and the Built Environment (2004b) Green Space Strategies, a Good Practice Guide. http://webarc hive.nationalarchives.gov.uk/20110118095356/, http://www. cabe.org.uk/files/green-space-strategies.pdf.

Crowhurst Lennard, S., and H. Lennard. 1995. Livable Cities Observed. Carmel CA: Gondolier Press.

Cullen, G. 1961. Townscape. London: Architectural Press.

Cho, Im Sik, Chye Kiang Heng, and Zdravko Trivic. 2016. Reframing Urban Space, Urban Design for Emerging Hybrid and High-Density Conditions. Routledge: Abingdon Oxon.

Gehl, J., and L. Gemzoe. 2000. New City Spaces. Copenhagen: The Danish Architectural Press.
Graham, S., and S. Marvin. 2001. Splintering Urbanism: Networked Infrastructures, Technological Mobilities and the Urban Condition. Routledge: Abingdon.

Habitat International Coalition. 1995. World Charter for the Right to the City. http://www.hic-gs.org/document.php?pid=3848.

Haile, C. 2012. A Myth of Urban Design: The 'Sense of Enclosure' Theory. http://www.chrishaile.com/2012/01/a-myth-of-urbandesign-the-sense-of-enclosure-theory/.

Hajer, M., and A. Reijndorp. 2001. In Search of New Public Domain. Rotterdam: NAI Publishers.

Jacobs, J. 1961, 1984 edition. The Death and Life of Great American Cities: The Failure of Modern Town Planning. London: Peregrine Books.

Lefebvrre, H. 1968. Le Droit à la Ville, Paris, Anthropos.

Light, A., and J. Smith. 1998. Philosophy and Geography II: The Production of Public Space. Lanham: Rowman and Littlefield.

Malone, K. 2002. "Street Life: Youth" Culture and Competing Uses of Public Space. Environment and Urbanization 14 (2): 157-168.

Mitchell, D. 1995. The End of Public Space? People's Park, Definitions of the Public Democracy. Annals of the Association of American Geographers 85 (1): 108-133.

Minton, A. 2009. Ground Control, Fear and Happiness in the Twenty-first Century City. London: Penguin Books.

Monclus, F. 2003. The Barcelona Model and an Original Formula? From 'Reconstruction' to Strategic Urban Projects (1979-2004). Planning Perspectives 18 (4): 399-421.

Nemeth, J. 2012. Controlling the Commons, How Public is Public Space? Urban Affairs Review 48 (6): 811-835.

New Economics Foundation. 2004. Clone Town Britain, The Loss of Local Identity on the Nation's High Streets. London: New Economics Foundation.

Newman, O. 1973. Defensible Space: People and Design in the Violent City. London: Architectural Press.

Sennett, R. 1990. The Conscience of the Eye, the Design and Social Life of Cities. New York: Alfred Knopf.

Sorkin, M. 2009. The End(s) of Urban Design. In Urban Design, ed. A. Krieger and S. Saunders. Minneapolis: University of Minnesota Press.

UN Habitat. 2013. Global Public Space Toolkit From Global Principles to Local Policies and Practice. Nairobi: United Nations Human Settlements Programme.

Webster, C. 2001. Gated Cities of Tomorrow. Town Planning Review 72 (2): 149-170. 